\title{
Impact of a local newspaper campaign on the uptake of the measles mumps and rubella vaccine
}

\author{
Brendan W Mason, Peter D Donnelly
}

Iechyd Morgannwg

Health, 41 High Street, Swansea, SA1 1LT, Wales

Correspondence to: Dr Mason (brendan.mason@ morgannwg-ha.wales.nhs.uk)

Accepted for publication 12 January 2000
Data on uptake of the measles mumps and rubella (MMR) vaccine in the United Kingdom are available through the COVER/Korner programme. ${ }^{12}$ The programme measures uptake of the MMR vaccine for children resident in a district on the evaluation date who reached their second birthday during the previous quarter. Children are scheduled to receive the first MMR immunisation at 12 months of age.

The latest data have demonstrated a decline of $1.4 \%$ in coverage of the MMR vaccine for children in the UK who reached their second birthday during the evaluation quarter (July to September 1998). ${ }^{3}$ This cohort of children were scheduled to receive MMR during a period when there was considerable national media interest in possible adverse effects of MMR.

Since July 1997 a protracted campaign against the MMR vaccine has been run by the South Wales Evening Post (SWEP), an evening newspaper sold in parts of two Health Authority areas (Morgannwg and Dyfed Powys). We report an investigation into MMR uptake in that area of distribution and compared it with uptake in the rest of Wales.

\section{Methods and results}

In Wales COVER statistics for the 14 trusts that provide community services are published quarterly by the Welsh Unit of the Public Health Laboratory Service Communicable Diseases Surveillance Centre. The distribution area of the SWEP (Swansea, Neath, Port Talbot and Llanelli) matches the localities served by two of these trusts. Coverage for the quarter July to September 1998 was compared with the same quarter a year previously in both the distribution area of the SWEP and the rest of Wales.

Uptake declined by $13.6 \%$ (95\% confidence intervals $10.9 \%$ to $16.2 \%$ ) in the distribution

Table 1 Uptake of the measles mumps and rubella vaccine

area of the SWEP and by $2.4 \% \quad(95 \%$ confidence intervals $1.4 \%$ to $5.5 \%$ ) in the rest of Wales. Before the campaign, uptake was significantly higher in the distribution area of the paper compared with the rest of Wales (difference $1.7 \%, 95 \%$ confidence intervals $0.1 \%$ to $3.4 \%)$. After the start of the campaign, uptake was significantly lower in the distribution area of the paper compared with the rest of Wales (difference $-9.4 \%, 95 \%$ confidence intervals $-7.1 \%$ to $-11.7 \%$ ) (table 1 ).

\section{Comment}

Uninformed and damaging press campaigns on the alleged dangers of childhood immunisation are not new. ${ }^{4}$ Nor are articles on the frustrations of the medical profession in countering these. ${ }^{5}$ However, we are unaware of any previous attempt to analyse in a quantitative way the impact of one local newspaper upon the uptake of a specific vaccine.

Adverse publicity in the SWEP started in July 1997 and developed into the "MMR Parent's fight for facts" campaign. During the period July to September 1997 the paper published five front page main headline articles, three opinions, and at least 18 other articles on the MMR vaccine. Subsequently at least six further front page main headlines, six opinions, and 22 other articles have been published.

The results demonstrate that while a drop off in uptake of the MMR vaccine occurred in the whole of Wales, there was a statistically significant greater decline in the distribution area of the SWEP. This suggests that the SWEP campaign has had a measurable and unhelpful impact over and above any adverse national publicity. A study of this type cannot prove a causal relation and an alternative explanation for the association between the adverse local publicity and the fall in uptake is possible. For

\begin{tabular}{llll}
\hline & $\begin{array}{l}\text { \% Uptake before campaign } \\
\text { (number vaccinated / target } \\
\text { population) }\end{array}$ & $\begin{array}{l}\text { \% Uptake after start campaign } \\
\text { (number vaccinated / target } \\
\text { population) }\end{array}$ & $\begin{array}{l}\text { \% Change in uptake (95\% } \\
\text { confidence intervals) }\end{array}$ \\
\hline $\begin{array}{l}\text { Distribution area of South Wales } \\
\quad \text { Evening Post }\end{array}$ & $91.0(1289 / 1417)$ & $77.4(1079 / 1394)$ & $-13.6(-16.2 \%$ to $-10.9 \%)$ \\
$\begin{array}{l}\text { Rest of Wales } \\
\begin{array}{l}\text { Difference in uptake between two } \\
\text { areas (95\% confidence }\end{array}\end{array}$ & $\begin{array}{l}89.2(6647 / 7450) \\
\text { intervals) }\end{array}$ & $\begin{array}{l}86.8(6715 / 7738) \\
-9.4 \%(-7.1 \% \text { to }-11.7 \%)\end{array}$ & $-2.4(-5.5 \%$ to $-1.4 \%)$ \\
\hline
\end{tabular}

*Apparent discrepancy results from rounding error $91.0 \%-89.2 \%=1.8 \%$, calculation on actual data $=1.7 \%$. 
example, a genuine problem with a vaccine in a particular area might result in both a fall in uptake and increased media coverage.

However, there is no problem with the MMR vaccine $^{6}$ and the SWEP campaign is the most likely explanation.

Conflicts of interest: none.

1 Begg NT, Gill ON, White JM. COVER (cover of vaccination evaluated rapidy): description of the England and Wales Scheme. Public Health 1989;102:81-9
2 White JM, Rush M, Leon S, et al. COVER/Korner 95-1 (April to June 1995) vaccination coverage statistics for children up to 2 years old in the United Kingdom. Commun Dis Rep CDR Rev 1995;5:R186-7.

3 Anonymous. MMR vaccine coverage falls in the United Kingdom. Commun Dis Rep CDR Wkly 1999;9:37.

4 Gangarosa EJ, Galazka AM, Wolfe CR, et al. Impact of antivaccine movements on pertussis control: the untold story. Lancet 1998;351:356-61.

5 Nicoll A, Elliman D, Ross E. MMR vaccination and autism 1998: Deja vu - pertussis and brain damage 1974? BMF 1998;316:715-16

6 Taylor B, Miller E, Farrington CP, et al. Autism and measles, mumps, and rubella vaccine: no epidemiological evidence for a causal association. Lancet 1999;353:2026-9. 